\title{
Traumatic vertebral artery injuries in the geriatric population: a retrospective cohort study
}

\author{
Paul S. Page, MD, and Darnell T. Josiah, MD \\ Department of Neurological Surgery, University of Wisconsin Hospitals and Clinics, Madison, Wisconsin
}

OBJECTIVE Traumatic vertebral artery injuries (TVAls) are a common finding in cervical spine trauma and can predispose patients to posterior circulation infarction. While extensive research has been conducted regarding the management and criteria for imaging in patients with suspected blunt vascular injury, little research has been conducted highlighting these injuries in the geriatric population.

METHODS The authors performed a retrospective review of all patients evaluated at a level 1 trauma center and found to have TVAls between January 1, 2010, and January 1,2018. Biometric, clinical, and imaging data were obtained from a trauma registry database. Patients were divided into 2 groups on the basis of age, a geriatric group (age $\geq 65$ years) and an adult group (age 18 to $<65$ years). Variables evaluated included type of trauma, mortality, Injury Severity Score (ISS), and ICU length of stay. The Student t-test was used for continuous variables, and Pearson's chi-square test was used for categorical variables.

RESULTS Of the 2698 of patients identified with traumatic cervical spine injuries, 103 patients demonstrated evidence of TVAI. Of these patients, 69 were $<65$ and 34 were $\geq 65$ years old at the time of their trauma. There was no difference in the incidence of TVAls between the 2 groups. The ICU length of stay ( 4.71 vs 4.32 days, $p>0.05$ ), hospital length of stay (10.71 vs 10.72 days, $p>0.05)$, and the ISS (21.50 vs $21.32, p>0.05)$ did not differ significantly between the 2 groups. Mortality was significantly higher in the geriatric group, occurring in 9 of 34 patients $(26.5 \%)$ compared with only 3 of 69 patients $(4.4 \%)$ in the adult group $(p<0.001)$. Ground-level falls were the most common inciting event in the geriatric group (44\% vs $14.5 \%, p<0.001)$, whereas motor vehicle accidents were the most common etiology in the younger population $(72.5 \%$ vs $38.2 \%, p<0.001)$. Incidence of ischemic stroke did not vary significantly between the 2 groups ( $p$ $>0.05)$.

CONCLUSIONS TVAI in the older adult population is associated with a significantly greater risk of mortality than in the younger adult population, despite the 2 groups having similar ISSs. Additionally, low-velocity mechanisms of injury, such as ground-level falls, are a greater risk factor for acquired TVAI in older adults than in younger adults, in whom it is a significantly less common etiology.

https://thejns.org/doi/abs/10.3171/2019.11.SPINE191055

KEYWORDS vertebral artery injuries; cervical spine trauma; neurotrauma

$\mathrm{B}$ LUNT cerebrovascular injury (BCVI) to the carotid or vertebral arteries following trauma occurs in up to $2.7 \%$ of blunt trauma patients, with some studies reporting incidence rates up to $50 \%$ for ischemic infarction following injury. ${ }^{1}$ Given the high morbidity and mortality associated with these lesions, extensive research has been conducted on screening protocols and ideal treatment strategies. The recently published Parkland Carotid and Vertebral Artery Surveys have greatly clarified the natural history of these lesions; however, the patients described in these studies are relatively young, with an aver- age age of 35 years at the time of their injury. ${ }^{11,12}$ While these studies were very well designed, the reliability of generalization of their findings to the geriatric population is limited. Many geriatric patients are at greater risk for cervical spine injury than younger patients due to their predisposition for underlying osteopenia and osteoporosis and the difference in their vascular mobility compared to that of their younger counterparts. Overall, close to 23\% of traumatic injuries occur in older adults, and overall this group represents the fastest-growing trauma population. ${ }^{5,7}$ We retrospectively reviewed all patients presenting with

ABBREVIATIONS BCVI = blunt cerebrovascular injury; ISS = Injury Severity Score; TVAI = traumatic vertebral artery injury.

SUBMITTED September 4, 2019. ACCEPTED November 8, 2019.

INCLUDE WHEN CITING Published online January 17, 2020; DOI: 10.3171/2019.11.SPINE191055. 
TABLE 1. Demographic and clinical characteristics of the patient groups

\begin{tabular}{lccc}
\hline & $\begin{array}{c}\text { Adult Group } \\
(\mathrm{n}=69)\end{array}$ & $\begin{array}{c}\text { Geriatric Group } \\
(\mathrm{n}=33)\end{array}$ & $\begin{array}{c}\mathrm{p} \\
\text { Value }\end{array}$ \\
\hline Mean age, yrs & 42.5 & 77.09 & \\
\hline Sex & & & 0.99 \\
\hline Male & 44 & 21 & \\
\hline Female & 25 & 12 & 0.99 \\
\hline Race & & & \\
\hline Asian & 1 & 0 & \\
\hline Black & 5 & 0 & 0.80 \\
\hline White & 62 & 30 & 1.0 \\
\hline Other & 1 & 3 & 0.71 \\
\hline ISS & 21.5 & 21.32 & $<0.001$ \\
\hline Hospital LOS, days & 10.7 & 10.7 & \\
\hline ICU LOS, days & 4.71 & 4.32 & \\
\hline Mortality & 3 & 9 & \\
\hline LOS & & & \\
\hline
\end{tabular}

LOS = length of stay.

Values are presented as number of patients unless otherwise indicated.

Boldface type indicates statistical significance.

traumatic vertebral artery injuries (TVAIs) at a regional level 1 trauma center to better define risk factors, natural history, and outcomes in geriatric patients following these injuries.

\section{Methods}

For all patients presenting with traumatic cervical spine injuries evaluated at the University of Wisconsin Hospital between January 2010 and January 2018, we conducted a retrospective patient chart review by examining the TraumaBase database maintained by Clinical Data Management. Trained trauma registrars enroll patients into this registry at the time of their initial traumatic encounters, according to guidelines of the national standards set by the National Trauma Data Bank and Trauma Quality Improvement Program, which is supported by the American College of Surgeons. In September 2018, we queried records from the selected time frame using definitions, appropriate ICD-9 codes, and Abbreviated Injury Scale scores from the data dictionary of the Data Bank of the 2016 National Trauma Data Standard. After we identified all patients with traumatic cervical spine injuries evaluated at our institution, these patients were then cross-referenced with patients suffering a vertebral artery injury. For all patients identified, ICD-9 codes were reviewed by the authors. Exclusion criteria included patients younger than 18 years and those without known trauma. All individual charts were reviewed, including patient Biffl Scale BCVI grades and Injury Severity Scores (ISSs), to better characterize trauma etiology, cervical spine pathology, classification of the blunt vertebral artery injury, treatment, and presence or absence of ischemic infarction. Following identification, the patients were divided on the basis of age into a geriatric population (age $\geq 65$ years) and an adult population (age 18 to $<65$ years). Neurological function
TABLE 2. Etiology of trauma resulting in patient presentation to the emergency department

\begin{tabular}{lccl}
\hline \multicolumn{1}{c}{ Trauma Etiology } & $\begin{array}{c}\text { Adult Group } \\
(\mathrm{n}=69)\end{array}$ & $\begin{array}{c}\text { Geriatric Group } \\
(\mathrm{n}=33)\end{array}$ & $\begin{array}{c}\mathrm{p} \\
\text { Value }\end{array}$ \\
\hline Ground-level fall & 2 & 15 & $\mathbf{0 . 0 0 1}$ \\
\hline Fall from height & 9 & 6 & 0.53 \\
\hline Motor vehicle accident & 46 & 13 & $\mathbf{0 . 0 0 6 1}$ \\
\hline Other & 3 & 0 & 0.22 \\
\hline
\end{tabular}

Values are presented as number of patients unless otherwise indicated. Boldface type indicates statistical significance.

outcomes were obtained through documentation of the results of each patient's physical examination at the time of discharge. Mortality was defined as death occurring during the same hospitalization immediately following the patient's trauma. IRB exemption was granted for this study as a medical records review.

\section{Statistical Analysis}

The Student t-test was used for continuous variables and the Pearson chi-square test was used for categorical variables in the statistical analyses. A $p$ value of $<0.05$ was deemed statistically significant for the purposes of this study. The Biffl Scale was used for grading of BCVIs, and the presence of ischemic stroke was included only if confirmed by MRI studies. ${ }^{3}$

\section{Results}

Of the 2698 patients identified with traumatic cervical spine injuries during the designated time frame, 1902 were 18 to $<65$ years old (adult group) and 796 were $\geq 65$ years old (geriatric group), and 103 patients demonstrated evidence of TVAI. Of the patients with TVAI, 69 were < 65 and 33 were $\geq 65$ years old at the time of their trauma $(3.62 \%$ vs $4.14 \%, p=0.52)$. There was no statistically significant difference in the incidence of TVAI between the 2 groups. For the adult group compared with the geriatric group, respectively, there were no significant differences between ICU length of stay (4.71 vs 4.32 days, $p>0.05$ ), hospital length of stay (10.71 vs 10.72 days, $p>0.05)$, and ISS (21.50 vs $21.32, \mathrm{p}>0.05)$. Mortality was significantly higher in the geriatric group, occurring in 9 of 34 patients (26.5\%) compared with only 3 of 69 patients $(4.4 \%)$ in the adult group ( $<<0.001$; Table 1). The etiologies of mortality in the adult group were intracranial hemorrhage (ICH) in 1 patient, spinal cord injury (SCI) in 1 patient, and ischemic stroke in 1 patient, and in the geriatric group were nonneurologic injuries in 3 patients, SCI in 2 patients, ischemic stroke in 1 patient, combined SCI and ICH in 1 patient, and ICH in 2 patients. The most common trauma etiologies were ground-level falls in the geriatric group (44\% vs $14.5 \%, \mathrm{p}<0.001)$ and motor vehicle accidents in the adult group (72.5\% vs $38.2 \%, \mathrm{p}<0.001$; Table 2 ).

In regard to BCVIs, which were assessed using the Biffl Scale, the most common BCVI overall was Biffl grade I dissection, occurring in 29 of 68 patients in the adult group and 12 of 33 in the geriatric group. In the geriatric 
TABLE 3. Distribution of TVAls according to the Biffl Scale for BCVIs

\begin{tabular}{lccc}
\hline $\begin{array}{c}\text { Biffl Scale } \\
\text { Grade }\end{array}$ & $\begin{array}{c}\text { Adult Group } \\
(\mathrm{n}=69)\end{array}$ & $\begin{array}{c}\text { Geriatric Group } \\
(\mathrm{n}=33)\end{array}$ & $\begin{array}{c}\mathrm{p} \\
\text { Value }\end{array}$ \\
\hline I & 29 & 12 & 0.4843 \\
\hline II & 12 & 3 & \\
\hline III & 1 & 2 & \\
\hline IV & 23 & 14 & \\
\hline Bilateral & 3 & 2 & \\
\hline
\end{tabular}

Values are presented as number of patients unless otherwise indicated.

group the most common BCVI was grade IV dissection, occurring in 14 of 33 patients compared with 23 of 68 in the adult group (Table 3). Overall there was no statistically significant difference in BCVI Biffl grades between the 2 groups. In addition, 6 ischemic infarctions occurred in the adult group compared with 3 in the geriatric group, a difference that was also not statistically significant $(\mathrm{p}>$ $0.05)$. In the geriatric group, 1 patient required endovascular coiling of a pseudoaneurysm, whereas 2 patients in the adult group required stenting procedures. One adult patient required decompressive craniectomy. Of the patients with cervical spine fractures, fractures at $\mathrm{C} 2$ were statistically significantly more common in the geriatric group than in the adult group (52.0\% vs $30.4 \%, \mathrm{p}=0.04$; Table 4).

\section{Discussion}

TVAI may occur following a wide variety of injuries, including fractures through the foramen transversarium, facet fracture dislocations, vertebral subluxations, stretchrelated injuries, and any other types of injuries that may result in abnormal mobilization of the artery. While the overall incidence of TVAI is estimated to be approximately $0.5 \%$ to $0.7 \%$ of patients suffering blunt injuries, this incidence increases to approximately $6 \%$ in patients with a cervical spine fracture or ligamentous injury. ${ }^{2}$ Given the relatively high incidence of these injuries associated with cervical spine fractures, it is imperative that healthcare providers be well versed in the natural history of these lesions, particularly in the increasing geriatric patient population. While much research has been conducted regarding the screening criteria for identifying these lesions and their overall natural history, little research has been conducted evaluating these lesions in the elderly population. It has been demonstrated that TVAI is more common in the younger adult population; however, geriatric patients have been reported to make up $20.2 \%$ of all trauma patients. ${ }^{6}$ One strength of our study is that the ISSs are very similar in these 2 groups. While the etiologies of injury in these 2 groups did demonstrate a significant difference, the ISSs demonstrate that the overall severities of injuries sustained in these groups, when accounting for the sums of their injuries in all body systems, are in fact directly comparable.

In the current literature, a relatively young average age of patients with TVAI is often cited, which makes it difficult to generalize findings related to patient care to the
TABLE 4. Distribution of cervical spine injuries based on level and type of injury

\begin{tabular}{cccc}
\hline & $\begin{array}{c}\text { Adult Group } \\
(\mathrm{n}=69)\end{array}$ & $\begin{array}{c}\text { Geriatric Group } \\
(\mathrm{n}=33)\end{array}$ & $\begin{array}{c}\mathrm{p} \\
\text { Value }\end{array}$ \\
\hline Fracture & 58 & 29 & 0.61 \\
\hline C1 & 13 & 2 & 0.09 \\
\hline C2 & 21 & 17 & 0.04 \\
\hline C3 & 5 & 2 & 0.82 \\
\hline C4 & 13 & 2 & 0.09 \\
\hline C5 & 14 & 4 & 0.31 \\
\hline C6 & 17 & 3 & 0.06 \\
\hline C7 & 13 & 3 & 0.21 \\
\hline Cervical strain & 6 & 4 & 0.59 \\
\hline Ligamentous injury & 3 & 0 & 0.22 \\
\hline Other & 2 & 0 & 0.32 \\
\hline
\end{tabular}

Values are presented as number of patients unless otherwise indicated.

Boldface type indicates statistical significance.

geriatric population. In the Parkland studies the average age of inclusion was 35 years for patients with Biffl grade I and II BCVI, followed by an average age of 42 years for grade III injuries and 48 years for grade IV injuries. ${ }^{11,12}$ In our study, the average age for the patients in the geriatric group was 77.1 years, and thus this patient group was much more representative of the geriatric patient population. In our overall patient population there was no statistically significant variability in the Biffl grades between the 2 age groups or their underlying risk of ischemic infarction. One study by Newhall et al. evaluated Medicare beneficiaries with discovered traumatic and vertebral artery dissections and found an overall stroke rate similar to that in our study of around 5\%.10

Despite the relatively low risk of ischemic infarction and low-velocity mechanisms of injury in the geriatric group, a high mortality rate was observed. In our study, the mortality rate in the adult group was approximately $3.5 \%$ and that for the geriatric group was 26.5\% (p < $0.001)$. The stroke rate did not vary significantly in these populations, however, and the ISSs in the adult and geriatric groups were essentially identical at 21.5 versus 21.3 , respectively. In the previously mentioned study by Newhall et al., the in-hospital mortality of $10.3 \%$ was also elevated compared to the frequently cited adult patient population mortality rate of $4 \%-8 \%{ }^{4,9,10}$ Given the complexities of polysystem trauma patients, the direct reasons for death in these patients are frequently multifactorial. It is also important to note that while low-energy traumas, such as ground-level falls, account for $50 \%$ or more of the traumas in the geriatric age group, this mechanism of injury has historically not been considered to pose a high risk for BCVI. ${ }^{6}$ Despite this, our study demonstrated ground-level falls as the most common inciting incident for presentation in the geriatric group. Given these findings, it can be inferred that TVAI carries an association with mortality in the elderly patient population.

TVAI commonly occurs at sites where vessels are exposed to shearing or tearing forces occurring at the junc- 
tion between the mobile and fixed segments of the vertebral arteries. ${ }^{13}$ In infants and children the $\mathrm{V}_{3}$ and upper $\mathrm{V}_{2}$ segments are especially susceptible, given the higher laxity of the ligaments in the craniocervical junction. ${ }^{4,8}$ In adults, however, TVAIs frequently occur following forced flexion/extension and lateral rotation of the cervical spine, and the $\mathrm{V}_{3}$ and $\mathrm{V}_{4}$ segments are more resistant to blunt trauma given the greater mobility in this region. In our study the geriatric patient group demonstrated a greater number of $\mathrm{C} 2$ fractures associated with TVAI than the adult group, a finding that demonstrated a more homogenous distribution of these injuries. While no definitive conclusions can be made regarding this relationship, one potential etiology is due to significant underlying atherosclerosis and vascular calcification in the older age group, which may result in limitation of the inherent mobility of the artery in this segment. With a reduction in mobility, greater shearing forces can be transmitted at this location, resulting in vascular dissection.

Our specific patient population, which was evaluated at a level 1 tertiary care facility utilizing the Denver Criteria as a standard for vascular imaging, has an inherent limitation secondary to the relatively small number of patients, which limits the identification of potentially significant associations. Geriatric patients who have sustained a ground-level fall are often treated at regional care facilities that obtain clinically appropriate imaging of the head and cervical spine but may not perform any vascular imaging, and thus a vast number of these patients often do not meet the criteria for a referral to a trauma center. Enhanced screening criteria may identify more patients suffering TVAI that would otherwise go undiagnosed. While the end point of death occurring during the same hospitalization is another limitation, our study was focused on the acute management of these patients and identifies potential risk factors for recovery from their initial trauma rather than long-term outcomes.

\section{Conclusions}

In summary, our study demonstrates that TVAI, even from low-energy mechanisms, potentially carries a higher risk for mortality in the older compared with the younger adult population. Low-velocity mechanisms of injury are frequently overlooked when considering TVAI, and this study highlights the common presentation of low-velocity mechanisms of injury in the geriatric population. In addition to these findings, this study highlights the differences in the underlying pathophysiology of TVAI in geriatric patients compared with younger adult patients.

\section{References}

1. Beliaev AM, Barber PA, Marshall RJ, Civil I: Denver screening protocol for blunt cerebrovascular injury reduces the use of multi-detector computed tomography angiography. ANZ J Surg 84:429-432, 2014

2. Berne JD, Norwood SH: Blunt vertebral artery injuries in the era of computed tomographic angiographic screening: incidence and outcomes from 8292 patients. J Trauma 67:1333-1338, 2009
3. Biffl WL, Moore EE, Elliott JP, Ray C, Offner PJ, Franciose $\mathrm{RJ}$, et al: The devastating potential of blunt vertebral arterial injuries. Ann Surg 231:672-681, 2000

4. Biffl WL, Moore EE, Offner PJ, Brega KE, Franciose RJ, Burch JM: Blunt carotid arterial injuries: implications of a new grading scale. J Trauma 47:845-853, 1999

5. Calland JF, Ingraham AM, Martin N, Marshall GT, Schulman CI, Stapleton T, et al: Evaluation and management of geriatric trauma: an Eastern Association for the Surgery of Trauma practice management guideline. J Trauma Acute Care Surg 73 (5 Suppl 4):S345-S350, 2012

6. Gioffrè-Florio M, Murabito LM, Visalli C, Pergolizzi FP, Famà F: Trauma in elderly patients: a study of prevalence, comorbidities and gender differences. G Chir 39:35-40, 2018

7. Gubler KD, Maier RV, Davis R, Koepsell T, Soderberg R, Rivara FP: Trauma recidivism in the elderly. J Trauma 41:952-956, 1996

8. Hasan I, Wapnick S, Tenner MS, Couldwell W: Vertebral artery dissection in children: a comprehensive review. Pediatr Neurosurg 37:168-177, 2002

9. Miller PR, Fabian TC, Bee TK, Timmons S, Chamsuddin A, Finkle R, et al: Blunt cerebrovascular injuries: diagnosis and treatment. J Trauma 51:279-286, 2001

10. Newhall K, Gottlieb DJ, Stone DH, Goodney PP: Trends in the diagnosis and outcomes of traumatic carotid and vertebral artery dissections among Medicare beneficiaries. Ann Vasc Surg 36:145-152, 2016

11. Scott WW, Sharp S, Figueroa SA, Eastman AL, Hatchette CV, Madden CJ, et al: Clinical and radiographic outcomes following traumatic Grade 3 and 4 carotid artery injuries: a 10-year retrospective analysis from a Level 1 trauma center. The Parkland Carotid and Vertebral Artery Injury Survey. J Neurosurg 122:610-615, 2015

12. Scott WW, Sharp S, Figueroa SA, Eastman AL, Hatchette CV, Madden CJ, et al: Clinical and radiographic outcomes following traumatic Grade 1 and 2 carotid artery injuries: a 10 -year retrospective analysis from a Level I trauma center. The Parkland Carotid and Vertebral Artery Injury Survey. J Neurosurg 122:1196-1201, 2015

13. Wang H, Orbach DB: Traumatic dissecting aneurysm at the vertebrobasilar junction in a 3-month-old infant: evaluation and treatment strategies. Case report. J Neurosurg Pediatr 1:415-419, 2008

\section{Disclosures}

The authors report no conflict of interest concerning the materials or methods used in this study or the findings specified in this paper.

\section{Author Contributions}

Conception and design: both authors. Acquisition of data: Page. Analysis and interpretation of data: Page. Drafting the article: both authors. Critically revising the article: both authors. Reviewed submitted version of manuscript: Page. Approved the final version of the manuscript on behalf of both authors: Page. Statistical analysis: Page. Administrative/technical/material support: Page. Study supervision: both authors.

\section{Correspondence}

Paul Page: University of Wisconsin Hospitals and Clinics, Madison,WI.page@neurosurgery.wisc.edu. 